\title{
PHYSICO-CHEMICAL AND CONDUCTIVITY STUDIES OF MICROCRYSTALLINE CELLULOSE (MCC) EXTRACTED FROM OIL PALM FRONDS AS A SUSCEPTIBLE FILLER IN PLA-LiTFSI POLYMER ELECTROLYTE
}

\section{HAZWAN HUSSIN*; IBRAHIM BELLO**; TUAN SHERWYN HAMIDON*; MOHAMAD ABU BAKAR*; AHMAD AZMIN MOHAMAD ${ }^{\ddagger}$ and M K MOHAMAD HAAFIZ ${ }^{\ddagger}$}

\begin{abstract}
The journey for sustainable solutions in the environment to create safe, cheap and assessable materials in society requires the use of more plant-based natural fibres in the industry. In this work, the acid hydrolysis process was adopted to isolate organosolv-microcrystalline cellulose (MCC) from oil palm fronds (OPF). Complementary analyses such as cross polarisation/magic angle spinning nuclear magnetic resonance (CP/ $\left.M A S{ }^{13} \mathrm{C} N M R\right)$, Fourier transform infrared spectroscopy (FT-IR), differential scanning calorimetry (DSC), thermogravimetric analysis (TGA), gel permeation chromatography (GPC), and X-ray diffraction (XRD) revealed extracted MCC bear a resemblance to commercial-MCC. Polymer solution casting technique was adopted to prepare different ratios of MCC-polylactic acid (PLA)-lithium bis(trifluoromethanesulfonyl)imide (LiTFSI) solid polymer electrolytes and electrical conductivities of polymer electrolyte films were investigated through electrochemical impedance spectroscopy (EIS). BO5 (organosolv-MCC-PLA-20 wt\% LiTFSI) showed the maximum ionic conductivity of $1.25 \times 10^{-5} \mathrm{~S} \mathrm{~cm}^{-1}$, while 5 wt\% 1-butyl-3-methylimidazolium chloride (BMIMCl) ionic liquid added revealed a positive effect of BMIMCl on the ionic conductivity of the polymer electrolyte yielding a higher conductivity of $2.3 \times 10^{-5} \mathrm{~S} \mathrm{~cm}^{-1}$.
\end{abstract}

Keywords: oil palm fronds, microcrystalline cellulose, polymer electrolyte.

Date received: 26 January 2019; Received in final form: 12 June 2019; Accepted: 19 June 2019.

\section{INTRODUCTION}

Since a few decades back, the focus given to batteries has mainly been on lithium-ion batteries. Nearly all

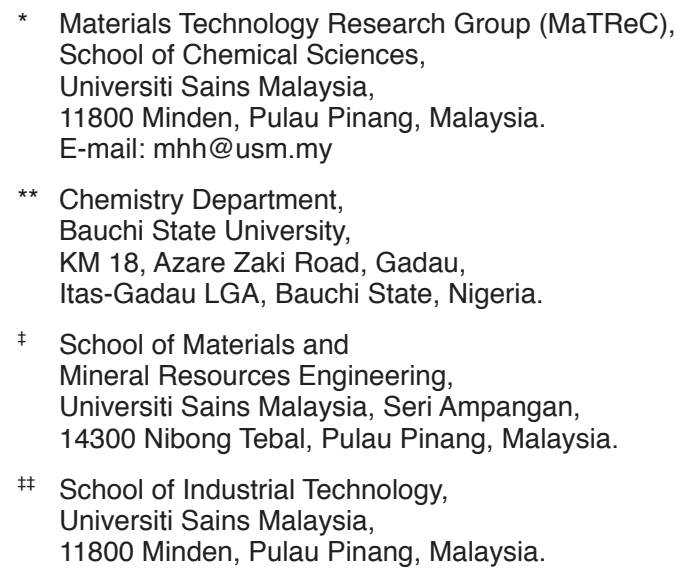

the research papers on batteries were essentially about enhancing lithium-ion battery performance. Among all batteries, lithium-ion batteries achieved enormous awareness due their ability to generate high energy density which makes them optimal for devices such as mobile phones, computers, solar cells, supercapacitors, biomedical sensors, electronic devices, temperature-sensitive and cameras (Bhat and Kumar, 2013; Vroman and Tighzert, 2009; Xu et al., 2005). Moreover, due to carbon dioxide emission, environmental pollution, the high cost of fossil fuels and global warming, the use of renewable resources to foster a sustainable bio-based economy serves beneficial socially and environmentally (Brosse et al., 2017). With the goal to reduce the greenhouse gas emission and to overcome the inadequacy of resources, a shift to employ bio-based matter instead has emerged (Nakagaito et al., 2009; Oksman et al., 
2006; Sanchez-Garcia and Lagaron, 2010; Teuber et al., 2016).

Utilisation of natural fibre as sustenance fillers in polymer matrices has attracted a lot of attention in recent past. It was reported that cellulose fibres incorporated into thermoset rubbery matrices could impart enhanced reinforcing potential than that of carbon or glass fibres (Ramayya et al., 1984). The potential factor behind this property is due to the resilience of the cellulose fibres as to brittle glass or carbon fibres which are less prone to damage during processing (Hamad, 2013).

Utilisation of cellulose as a green filler in polypropylene (PP) (Xiuju et al., 2011) and poly(ethylene terephthalate)-poly (trimethylene terephthalate) (PET-PTT) polymer matrices (Kiziltas et al., 2010) paves the ability to develop environmental-friendly composites. Additionally, Rathod et al. (2015) examined the application of lithium perchlorate $\left(\mathrm{LiClO}_{4}\right)$ doped-polyvinyl alcohol (PVA)/modified cellulose composites, where an optimum conductivity of $9.79 \times 10^{-6} \mathrm{~S} \mathrm{~cm}^{-1}$ was attained at $20 \mathrm{wt} \%$ doping of $\mathrm{LiClO}_{4}$. An optimum ionic conductivity of $2.83 \times 10^{-5} \mathrm{~S} \mathrm{~cm}^{-1}$ at ambient room temperature for a proton-conducting polymer electrolyte, attributed to starch and ammonium nitrate was noted by Khiar and Arof (2010). According to their findings, conductivity increased with the increment in the number of migrant ions. Furthermore, polylactic acid (PLA) was employed in producing nanocomposites with layered silicate (Rhim, 2007). Meanwhile, Mohamad Haafiz et al. (2013b) produced biodegradable composites by blending PLA with microcrystalline cellulose (MCC), consequently showed better mechanical properties to that of pure PLA.

Recent research studies reported the utilisation of MCC in the preparation of composites using various polymer matrices (Hussin et al., 2018; Kiziltas et al., 2010; Thummanukitcharoen et al., 2012; Xiuju et al., 2011). Mathew et al. (2005) examined the mechanical properties and crystallinity of MCC and PLA composites and biodegradation of the composites produced. It is believed that the blending of MCC into polymer matrices enhances the physical properties of the produced blend which may reflect on the larger size of MCC in comparison to nano-cellulose fibres (Miao and Hamad, 2013). The concern of low conductivity has been addressed by adding different types of salts, which have more conducting structures by the addition of ionic liquids as proposed by several scientists (Ramesh et al., 2008; Shin et al., 2003) but low conductivity at ambient room temperature still prevails (Shin et al., 2003).

The accumulation of oil palm fronds (OPF) biomass waste has created a significant disposal problem which may cause potential adverse impact to the ecosystem if it is not effectively exploited. Meanwhile, the existing polymer electrolytes nowadays endure inferior mechanical stability performance (Chew et al., 2013). Utilisation of MCC isolated from OPF is believed to elevate the performance and stability of polymer electrolytes. OPF materials could also be a promising alternative to non-biodegradable fossil fuels in fabricating solid polymer electrolytes.

No comprehensive research study as far as we know has been carried out on the utilisation of MCC as a cellulose-based green filler extracted from OPF to formulate lithium bis(trifluoromethanesulfonyl)imide (LiTFSI) salt doped PLA/MCC solid polymer electrolytes. Therefore, this study attempted to prepare solid polymer electrolytes about PLA blended with MCC and LiTFSI salts were developed via a polymer solution casting technique. Polymer electrolyte films' ionic conductivities were investigated via electrochemical impedance spectroscopy (EIS). The 1-butyl-3-methylimidazolium chloride (BMIMCl) ionic liquid was used to study its effect on the conductivity performance of the optimised polymer electrolyte film. Optimised polymer electrolyte film was characterised using Fourier transform infrared spectroscopy (FT-IR), differential scanning calorimetry (DSC) and X-ray diffraction (XRD) techniques, while extracted MCC was characterised via complementary analyses such as cross polarisation/magic angle spinning nuclear magnetic resonance (CP/MAS ${ }^{13} \mathrm{C} \mathrm{NMR}$ ), FT-IR, DSC, thermogravimetric analysis (TGA), gel permeation chromatography (GPC) and XRD.

\section{EXPERIMENTAL}

\section{Chemicals}

Analytical grade reagents and chemicals used in this study were hydrochloric acid, 37\% $\mathrm{HCl}$ (QRec, Malaysia); acetic acid, HOAc (QRec, Malaysia); sulphuric acid, $\mathrm{H}_{2} \mathrm{SO}_{4}$ (QRec, Malaysia); toluene, $\mathrm{C}_{7} \mathrm{H}_{8}$ (QRec, Malaysia); sodium hydroxide pellets, ethanol, EtOH (QRec, Malaysia); methanol, $\mathrm{MeOH}$ (QRec, Malaysia); sodium chlorite, $\mathrm{NaClO}_{2}$ (SigmaAldrich, United States); PLA (Sigma-Aldrich, United States); glycerol, $\mathrm{C}_{3} \mathrm{H}_{8} \mathrm{O}_{3}$ ( $\mathrm{HmbG}$, Malaysia); LiTFSI (Sigma-Aldrich, United States); phenyl isocyanate, $\mathrm{C}_{6} \mathrm{H}_{5} \mathrm{NCO}$ (Merck KGaA, Germany) and anhydrous pyridine, $\mathrm{C}_{5} \mathrm{H}_{5} \mathrm{~N}$ (Sigma-Aldrich, United States). Distilled water was used to prepare all the solutions.

\section{Materials}

OPF samples were collected from an oil palm plantation located at Nibong Tebal, Pulau Pinang, Malaysia in mid-2016. Strands were cut into small pieces and sun-dried for two days. Next, it was 
ground into a fine powder using a grinder (Model RT-34, Wiley). To ensure complete dryness, OPF samples were subjected to heat treatment in an oven for $24 \mathrm{hr}$ at $50^{\circ} \mathrm{C}$. Soxhlet extraction was carried out for the OPF biomass using ethanol: $\mathrm{C}_{7} \mathrm{H}_{8}$ volume ratio of 2:1 for $6 \mathrm{hr}$ before removing the extractives.

\section{Organosolv Pulping Process}

A mass of $25 \mathrm{~g}$ of the biomass obtained was combined with waste cooking oil consisting of $65 \%$ (v/v) EtOH and $1 \%(\mathrm{w} / \mathrm{w}) \mathrm{H}_{2} \mathrm{SO}_{4}$ as the catalyst in a 1 litre reactor pertaining reported method by El Hage et al. (2009) with slight modifications. The mixture carried a solid to liquid ratio of 1:8. Next, the mixture was subjected to heat treatment at $180^{\circ} \mathrm{C}$ for $1 \mathrm{hr}$. Upon heat treatment, the remaining fibrous material was washed three times $(3 \mathrm{ml} \times 50 \mathrm{ml})$ with moderately hot (about $\left.50^{\circ} \mathrm{C}\right)$ aqueous ethanol $(20 / 80$ $\mathrm{v} / \mathrm{v}$ ). Finally, vacuum filtration was carried out to filter the pulp and then oven dried for $24 \mathrm{hr}$ at $50^{\circ} \mathrm{C}$.

\section{Pulp Bleaching}

To carry out the bleaching process, a mass of $5 \mathrm{~g}$ of the pulp was mixed with $140 \mathrm{ml}$ of distilled water contained in a $250 \mathrm{ml}$-conical flask. The reaction mixture was further added with $3.5 \mathrm{ml}$ of glacial HOAc and $3.5 \mathrm{~g}$ of $\mathrm{NaClO}_{2}$. Next, it was subjected to heating at $80^{\circ} \mathrm{C}$ for $1.5 \mathrm{hr}$ while it was stirred continually (Timilsena et al., 2013). Upon filtration, holocellulose obtained was washed throughly using distilled water and oven dried at $50^{\circ} \mathrm{C}$ overnight.

\section{Mercerisation and Acid Hydrolysis}

In order to carry out the mercerisation process, a mass of $3 \mathrm{~g}$ of dried holocellulose was mixed with $10 \% \mathrm{NaOH}(150 \mathrm{ml})$ and stirred for $45 \mathrm{~min}$ at $30^{\circ} \mathrm{C}$. The resulted slurry was added with $150 \mathrm{ml}$ of distilled water and further stirred for $30 \mathrm{~min}$. The resulted $\alpha$-cellulose pulp (Hussin et al., 2018) was filtered under vacuum filtration and washed with 2\% (w/v) HOAc and 5\% (w/v) NaOH. Before proceeding to dry in an oven for $24 \mathrm{hr}$ at $50{ }^{\circ} \mathrm{C}$, the sample was washed thoroughly with distilled water (Hussin et al., 2016).

The process described by Chauhan et al. (2009) was employed in the production of microcrystalline cellulose with slight modifications. After obtaining completely dried $\alpha$-cellulose, the sample was hydrolysed using $3 \mathrm{M} \mathrm{HCl}$ at $70^{\circ} \mathrm{C}$ for $60 \mathrm{~min}$, accompanying a 1:30 $(\mathrm{w} / \mathrm{v})$ ratio of solid:liquor. Next, the sample was filtered again and treated with $5 \%$ mass concentration of $\mathrm{NaOH}$ and washed thoroughly with distilled water. Upon complete drying in an oven operated at $50^{\circ} \mathrm{C}$, the sample was ground to a fine particle size using mortar and pestle.

\section{Polymer Electrolyte Preparation}

Polymer electrolyte film was produced based on the method illustrated by Sudhakar and Selvakumar (2012) with slight modifications. Initially, $2 \mathrm{~g}$ of PLA and $0.5 \mathrm{~g}$ of MCC carrying a weight ratio of 80:20 were dissolved in $50 \mathrm{ml}$ of chloroform while being stirred firmly at $40^{\circ} \mathrm{C}$ for $2 \mathrm{hr}$ to produce a uniform solution. Upon $2 \mathrm{hr}$ of vigorous stirring, the mixture was added with $1.0 \mathrm{~g}$ of glycerol as the chelating agent with the successive addition of different mass compositions of $\operatorname{LiTFSI}(0,5,10,15$ and $20 \mathrm{wt} \%)$. Once the reaction mixture evolved into a highly viscous form with continuous stirring (blending) at $40^{\circ} \mathrm{C}$ for $3 \mathrm{hr}$, it was cast onto a Petri dish. After drying the Petri dish in an oven at $50^{\circ} \mathrm{C}$ for $24 \mathrm{hr}$, it was dried in the air to reach $30^{\circ} \mathrm{C}$ before removing the solid film off the Petri dish. Solid film's thickness was calculated at a $0.001 \mathrm{~mm}$ accuracy with the aid of a vernier caliper (Sudhakar and Selvakumar, 2012).

\section{Characterisation of MCC}

FT-IR analysis. FT-IR analysis was conducted via $\mathrm{KBr}$ disc method on a Perkin-Elmer System 2000 spectrometer. $\mathrm{KBr}$ discs were prepared to contain $1 \%$ of the samples. Data acquisition parameters of the analysis were $4000-400 \mathrm{~cm}^{-1}$ of wavelength range at $4.0 \mathrm{~cm}^{-1}$ resolution with 32 scans. Integration of each peak area was carried out using Perkin Elmer Spectrum software.

CP/MAS ${ }^{13} \mathrm{C}$ NMR study. High-resolution solidstate $\mathrm{CP} / \mathrm{MAS}{ }^{13} \mathrm{C} \mathrm{NMR}$ technique was executed using a Bruker Avance $400 \mathrm{MHz}$ spectrometer. All the analyses were performed at ambient room temperature with the aid of a Bruker 4-mm MAS probe. Spectra obtained were executed at 10000 scans per sample and processed offline using TopSpin 3.5 Bruker software.

Analysis using GPC. Masses of $20 \mathrm{mg}$ of each dried cellulose and MCC sample were added into a $50 \mathrm{ml}$ flask with the subsequent addition of 6 $\mathrm{ml}$ anhydrous pyridine along with $1 \mathrm{ml}$ phenyl isocyanate, before sealing the flask with a PTFElined closed cap. Then the sealed $25 \mathrm{ml}$ flask was subjected to heating in an oil bath at $80^{\circ} \mathrm{C}$ with continuous stirring for $40 \mathrm{hr}$. Once the reaction has completed, the mixture was air-dried to reach ambient room temperature, and $1.5 \mathrm{ml}$ of methanol was incorporated to suppress leftover phenyl isocyanate. Afterwards, the content was added into a mixture containing 7:3 volume ratio of methanol:water, to precipitate the derivatised cellulose (cellulose tricarbanilate).

Next, precipitated cellulose tricarbanilate (CTC) was centrifuged with successive washing 
using methanol: water (7:3), followed by water and lyophilised subsequently. Number average molecular weight number $\left(M_{n}\right)$ and weight average molecular weight $\left(M_{w}\right)$ of cellulose were calculated via GPC using a Binary HPLC Pump equipped with refractive index (RI) detector adopting an eluent of tetrahydrofuran (THF). Polystyrene standards were utilised to establish the calibration curve. Waters Breeze System software was employed to acquire and process the data. Number-average degree of polymerisation $\left(D P_{n}\right)$ and weight-average degree of polymerisation $\left(D P_{w}\right)$ was calculated through the division of $M_{n}$ and $M_{w}$ values respectively by 519 (the monomer equivalent weight of CTC) (Foston et al., 2011). The polydispersity index (PDI) was obtained through the division of $M_{w}$ by $M_{n}$.

XRD analysis. X-ray diffractometer (PANalytical X'Pert PRO MRD PW 3040) was used to conduct XRD analysis. Diffractograms were obtained employing $\mathrm{Cu}-\mathrm{K} \alpha$ radiation of $40 \mathrm{kV}$ and $40 \mathrm{~mA}$. The organosolv and commercial MCC samples were prepared as pellets with a diameter of $25 \mathrm{~mm}$ utilising a hydraulic press under $50 \mathrm{MPa}$ pressure (Azubuike and Okhamafe, 2012). Equation (1) outlined by Segal et al. (1959) was employed to evaluate the crystallinity index $(\mathrm{CrI})$ of MCC samples. Integration of the XRD data was executed using Microcal Origin 6.0 software.

$$
\operatorname{CrI}(\%)=\frac{\left(\mathrm{I}_{\mathrm{am}}-\mathrm{I}_{002}\right)}{\mathrm{I}_{002}} \times 100
$$

Equation (1)

where:

CrI - the relative degree of crystallinity.

$\mathrm{I}_{002}$ - the highest intensity of 002 lattice plane diffraction at $2 \theta=22.7^{\circ}$ (cellulose I).

$I_{a m}$ - intensity of diffraction associated to amorphous cellulose at $18^{\circ}$ of $2 \theta$ for cellulose I (Azubuike and Okhamafe, 2012).

Thermal analysis. Perkin-Elmer, model TGA 7 analyser was employed to evaluate the thermal properties of MCC samples. The specimens were heated in the range of $30^{\circ} \mathrm{C}$ to $900^{\circ} \mathrm{C}$ using a $10^{\circ} \mathrm{C} \mathrm{min}^{-1}$ heating rate under nitrogen and held for $5 \mathrm{~min}$ at $900^{\circ} \mathrm{C}$. Melting temperatures of the samples were acquired on a differential scanning calorimeter (Perkin Elmer Pyris 1). Samples were firmly fixed in an $\mathrm{Al}$ pan and heated in the range of $30^{\circ} \mathrm{C}$ to $400^{\circ} \mathrm{C}$ using a $10^{\circ} \mathrm{C} \mathrm{min}^{-1}$ heating rate under nitrogen gas atmosphere.

Brunauer-Emmett-Teller (BET) surface analysis. Elucidation of pore parameters, BET surface area and external surface area of organosolv and commercial MCC samples were carried out via Quantachrome Nova Win2 ${ }^{\odot}$ 1994-2002 software with the aid of BET equation.
EIS analysis. EIS analyses of the blend composites were performed on a HIOKI 3522-50 LCR HiTester. HIOKI 3522-50 LCR HiTester impedance unit was utilised to acquire the ionic conductivity of the prepared film at a broad frequency region of 1 $\mathrm{MHz}-1 \mathrm{~Hz}$ with an amplitude of $10 \mathrm{mV}$. EIS data were modelled using an equivalent electrical circuit obtained from ZSim Demo software. Equation (2) (Khiar and Arof, 2010) was exploited to evaluate the ionic conductivity values $(\sigma)$ of the blend composites.

$$
\sigma=\frac{L}{R_{b} A}
$$

Equation (2)

where:

$L$ - the thickness of the film (in $\mathrm{cm}$ ).

$A$ - exposed surface area.

$R_{b}$ - polymer electrolyte's bulk resistance $\left(\Omega \mathrm{cm}^{2}\right)$.

Effect of 5 wt\% BMIMCl ionic liquid. Five wt $\%$ BMIMCl was employed to study the effect of ionic liquid on the ionic conductivity performance of the optimised polymer electrolyte. A mass of $0.25 \mathrm{~g}$ (5 $\mathrm{wt} \%$ ) of BMIMCl was added dropwise into $50 \mathrm{ml}$ of the optimised polymer electrolyte gel mixture. The viscous mixture was then stirred vigorously at $40^{\circ} \mathrm{C}$ for $3 \mathrm{hr}$ until complete dissolution was achieved. The obtained gel solution was immediately casted onto a Petri dish and was covered with an aluminium foil. The film was placed in an oven at $50^{\circ} \mathrm{C}$ for $24 \mathrm{hr}$ before carrying out EIS analysis.

\section{RESULTS AND DISCUSSION}

\section{Cellulose Extractability}

The cellulosic yield obtained from the organosolv pulping process resulted in a hemicellulose content of $16.42 \pm 0.1 \%$, and cellulose content of $50.59 \pm 0.1 \%$. Based on the cellulosic product yield, it can be deduced that the organosolv pulping process is much more efficient in partitioning lignocellulosic raw materials into a water-soluble hemicellulose stream, celluloserich pulp, and a solid organosolv-lignin portion (Hussin et al., 2013).

\section{Characterisation of MCC}

FT-IR analysis. IR spectra were acquired to define the chemical structure of MCC by determining its functional groups. The relative absorbance measurements of various peaks were found out per the baseline correction method to draw a comparison between the spectra obtained (Adel et al., 2011). The vibrational assignments are compiled in Table 1, while the FT-IR spectra of organosolv and commercial MCC samples are displayed in 


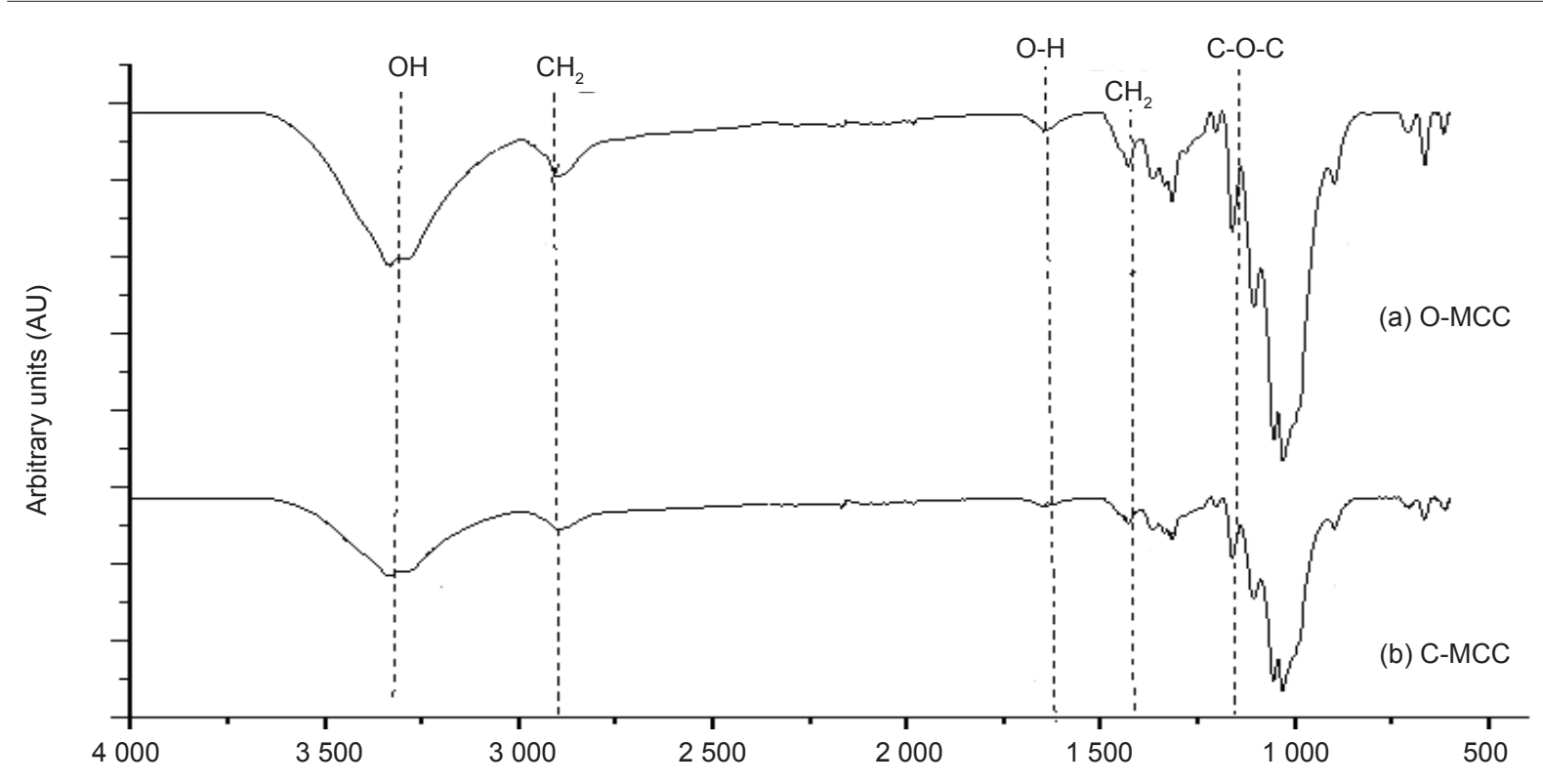

Figure 1. Fourier transform infrared spectroscopy (FT-IR) spectra of (a) organosolv-microcrystalline cellulose (MCC) and (b) commercial-MCC.

Figure 1. FT-IR analysis (Figure 1) made evident on the resemblance among the two spectra, which indicated that organosolv-MCC and commercialMCC have almost similar chemical composition. These similarities are comparable with the previous findings (Elanthikkal et al., 2010; Gonzalez-Rivera et al., 2014; Haafiz et al., 2014; Mohamad Haafiz et al., 2013a; Wu et al., 2014).

TABLE 1. FOURIER TRANSFORM INFRARED SPECTROSCOPY (FT-IR) SPECTRAL PEAK ASSIGNMENT FOR ORGANOSOLV-MICROCRYSTALLINE CELLULOSE (MCC) AND COMMERCIAL-MCC

\begin{tabular}{cl}
\hline Wavenumber $\left(\mathrm{cm}^{-1}\right)$ & Peak assignment \\
\hline $3300-3500$ & $-\mathrm{OH}$ stretching \\
$2800-3000$ & $\mathrm{CH}_{2}$ groups \\
1646 & $\mathrm{O}-\mathrm{H}$ bending \\
1431 & $\mathrm{CH}_{2}$ bending \\
$1163-1200$ & $\mathrm{C}-\mathrm{O}-\mathrm{C}$ stretching \\
$895-900$ & $\mathrm{C}-\mathrm{H}$ rock \\
801 & $\mathrm{C}-\mathrm{H}$ bending and \\
& ring puckering \\
\hline
\end{tabular}

Absorption bands of 3345, 2900, 1431, 1375, and $895 \mathrm{~cm}^{-1}$, are some of the characteristic bands manifested by cellulose type I (Mohamad Haafiz et al., 2013a). The IR peak positioned between $3300-3500 \mathrm{~cm}^{-1}$ is due to $\mathrm{OH}$-stretching vibration while $2800-2900 \mathrm{~cm}^{-1}$ represent $\mathrm{CH}_{2}$ groups. The absence of absorption peaks between $1513-1731 \mathrm{~cm}^{-1}$ indicates the loss of lignin, pectin and hemicellulose in the treated fibre (Elanthikkal et al., 2010). Based on previous work, the bands associated with 1430, 1330-1369 and $1163 \mathrm{~cm}^{-1}$ correspond to C6 group's hydrogen bonding (intermolecular), bending vibration of $\mathrm{C}-\mathrm{H}$ and $\mathrm{C}-\mathrm{O}$, and stretching vibration of C-O-C, respectively (Mohamad Haafiz et al., 2013a).
Furthermore, the IR signal present at $824 \mathrm{~cm}^{-1}$ of the commercial-MCC refers to C-H bending and ring of an arene. The vibration band positioned at $1431 \mathrm{~cm}^{-1}$ implies symmetric $\mathrm{CH}_{2}$ bending that shows an increase in MCC, designated 'crystallinity band' (Kalita et al., 2013), where an increment in the intensity corresponds to a greater extent of structural order. Moreover, IR peak located between 1160-1190 $\mathrm{cm}^{-1}$ illustrates C-O-C group's stretching vibration while absorption signal located between 890-910 $\mathrm{cm}^{-1}$ depicts $\mathrm{C}-\mathrm{H}$ rocking bonding mode of cellulose in organosolv-MCC and commercial-MCC samples (Li et al., 2009).

CP/MAS ${ }^{13} C$ NMR study. NMR uses radio frequency waves to stimulate transitions between nuclear energy levels. NMR being a non-destructive technique, cater properties such as chemical structure and composition of the matter studied. The structure of cellulose and its spectral analysis have been studied by many researchers (Chunilall et al., 2013; Miura and Nakano, 2016; Zhu et al., 2015). MCC samples' CP/MAS ${ }^{13} \mathrm{C}$ NMR spectra are demonstrated in Figure 2, where the assigned peaks were in line with previous literature (Diakité et al., 2013; Merci et al., 2015; Song et al., 2014).

Based on the NMR analysis of MCC samples, the resonance lines of $\mathrm{C} 1, \mathrm{C} 4$, and $\mathrm{C} 6$ carbon peaks were easily assigned since they were separated from each other. The resonance line at $\sim 105 \mathrm{ppm}$ was assigned as $\mathrm{C} 1$, while $\mathrm{C} 2, \mathrm{C} 3$, and $\mathrm{C} 5$ carbon peaks were overlapped to some extent with each other in the resonance range of 70-80 ppm (Newman and Hemmingson, 1995). The signals close to $90 \mathrm{ppm}$, indicative of $\mathrm{C} 4$ carbons, correspond to crystalline/ paracrystalline regions and signals from 80 to 85 ppm represent amorphous regions (Trache et al., 2014). 


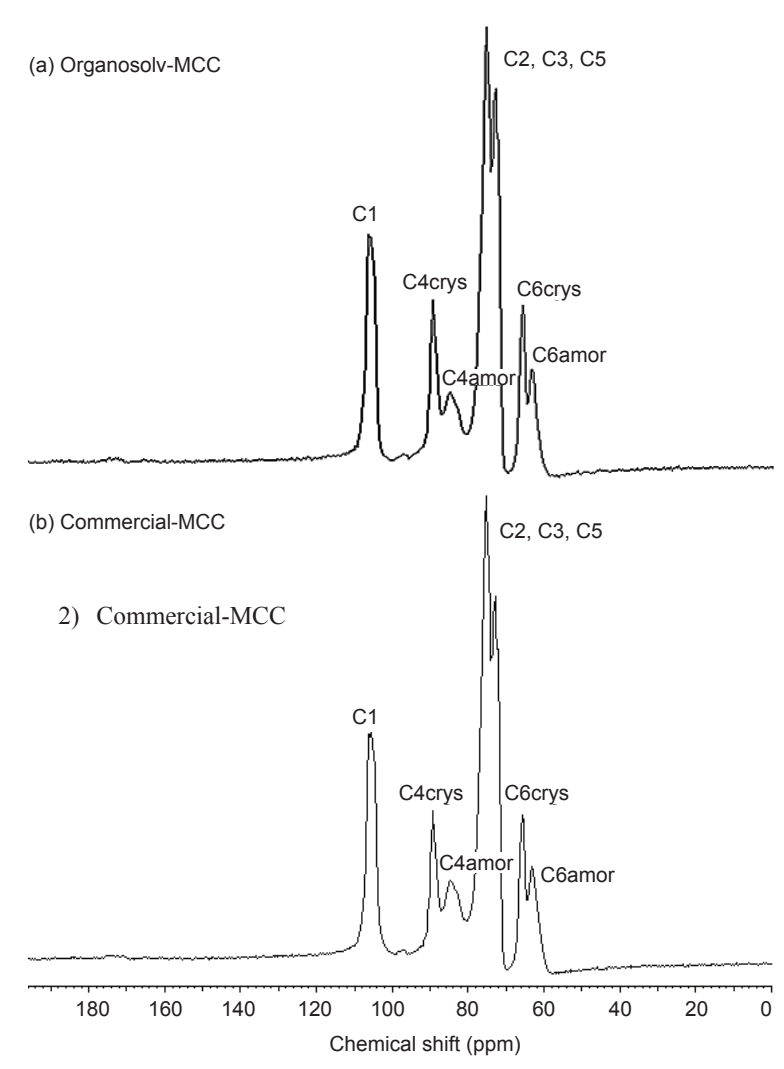

Figure 2. Solid-state cross polarisation/magic angle spinning nuclear magnetic resonance $\left(C P / M A S{ }^{13} \mathrm{C} N M R\right)$ spectra of (a) organosolvmicrocrystalline cellulose (MCC) and (b) commercial-MCC.

The intense crystalline region peaks of $\mathrm{C} 4$ and C6 carbons validated that the crystallinity properties of cellulose products could increase due to acid hydrolysis. Similar findings for MCC isolated from Alfa fibres were described by Trache et al. (2014).

Analysis using GPC. GPC is a formidable as well as most often used technique to separate polymers attributed to the size. The information obtained from the GPC analysis is useful in understanding more on the properties of the cellulose hydrolysis (Engel et al., 2012). The $M_{w^{\prime}} M_{n^{\prime}}$ and polydispersity of OPF cellulose (as control), commercial and organosolv MCC are outlined in Table 2. According to Table 2, decreased $M_{w}$ value of organosolv-MCC could be owing to the split of glycosidic bonds which results in the depolymerisation of cellulose. According to GPC analysis, organosolv-MCC yielded a lesser PDI compared to commercial-MCC, justifying that the hydrolysis reaction carried out using $2 \mathrm{M} \mathrm{HCl}$ was responsible for the formation of tiny chips of cellulose (Hussin et al., 2016).

XRD analysis. XRD diffractograms of commercial and organosolv MCC are displayed in Figure 3. Table 3 lists the evaluated $\mathrm{CrI}$ values of the cellulosic samples. According to X-ray diffractograms shown in Figure 3, cellulosic materials encountered in this study exhibited $2 \theta$ angle peaks at $15.7^{\circ}$ and $22.4^{\circ}$, representing amorphous and crystalline regions. Degradation of amorphous regions of lignocellulose materials, when subjected to mineral acids, is due to the splitting of polymer glycosidic bonds in the attainable locality of the molecules (Adel et al., 2010). Thus, MCC samples acquired from OPF consisted of a crystal lattice (cellulose type I).

It was revealed that organosolv-MCC displays higher crystallinity compared to that of commercial$\operatorname{MCC}\left(\mathrm{CrI}_{\text {organosolv-MCC }}: 76.51 \%>\mathrm{CrI} I_{\text {commercial-MCC }} 74.98 \%\right)$, which could be due to the organosolv pulping process producing cellulose-rich pulp (Hussin et al., 2013). Hussin et al. (2016) suggested that the enhanced crystallinity of cellulose increases their stiffness, leading to enhanced mechanical properties of cellulose-based composites. Azubuike and Okhamafe (2012) proposed that high crystallinity is indicative of well-organised molecular structure which corresponds to dense particles.

TABLE 2. PARAMETERS OBTAINED FROM THE GPC ANALYSIS FOR THE COMMERCIAL AND ORGANOSOLV MICROCRYSTALLINE CELLULOSE (MCC)

\begin{tabular}{cccccc}
\hline Sample & $\begin{array}{c}\boldsymbol{M}_{n} \\
\left(\mathbf{g ~ m o l}^{-1}\right)\end{array}$ & $\begin{array}{c}\boldsymbol{M}_{w} \\
\left(\mathbf{g ~ m o l}^{-1}\right)\end{array}$ & $\mathbf{P D I}$ & $\mathbf{D P}$ & $\mathbf{D P}_{w}$ \\
\hline Organosolv-MCC & 722 & 11824 & 1.64 & 13.91 & 22.78 \\
Commercial-MCC & 9457 & 17237 & 1.83 & 18.22 & 33.21 \\
\hline
\end{tabular}

Note: $M_{n}$ - number-average molecular weight. $M_{w}$ - weight-average molecular weight. $P D I$ - polydispersity index.

$D P_{n}$ - number-average degree of polymerisation. $D P_{w}$ - weight-average degree of polymerisation. GPC - gel permeation chromatography.

TABLE 3. CRYSTALLINITY INDEX, CRI (\%) OF COMMERCIAL AND ORGANOSOLV MICRO CRYSTALLINE CELLULOSE (MCC)

\begin{tabular}{cccc}
\hline Sample & $\begin{array}{c}\text { Lattice } \\
\text { plane } \\
\left(\boldsymbol{I}_{002}\right)\end{array}$ & $\begin{array}{c}\text { Amorphous } \\
\text { phase } \\
\left(I_{a m}\right)\end{array}$ & $\begin{array}{c}\text { Crystallinity } \\
\text { index } \\
(\mathrm{Cr} \boldsymbol{T} \%)\end{array}$ \\
\hline Organosolv-MCC & 1222 & 287 & 76.51 \\
Commercial-MCC & 1335 & 334 & 74.98 \\
\hline
\end{tabular}

Thermal behaviour analysis. Examining the thermal properties of MCC is vital to know the weight loss related to the temperature of thermal degradation, for its application as reinforcement for biocomposites materials. It is a useful technique to study polymeric materials including composites and fibres (Narayanan and Laine, 1997; Tikhonov et al., 2009). TGA analysis of commercial and organosolv MCC samples was carried out from $30^{\circ} \mathrm{C}-900^{\circ} \mathrm{C}$ (Figure 4) whereit showed two steps of mass loss in the temperature range of $50^{\circ} \mathrm{C}-100^{\circ} \mathrm{C}$ and $250^{\circ} \mathrm{C}-350^{\circ} \mathrm{C}$, respectively ( $\mathrm{Li}$ et al., 2009). The first stage $\left(50^{\circ} \mathrm{C}-100^{\circ} \mathrm{C}\right)$ was due to the loss of surface-bound water of MCC samples (Tikhonov et al., 2009), while the significant decomposition in the 
region of $250^{\circ} \mathrm{C}-350^{\circ} \mathrm{C}$ signified the decomposition of cellulose followed by conversion to char (Jonoobi et al., 2011). The lower decomposition temperature exhibited by organosolv-MCC could be due to the radical decline in its molecular weight. Moreover, MCC would expect to have a higher weight loss upon acid hydrolysis, possibly related to microcrystal sized cellulose's high purity which corroborates higher thermal stability (Mohamad Haafiz et al., 2013a).

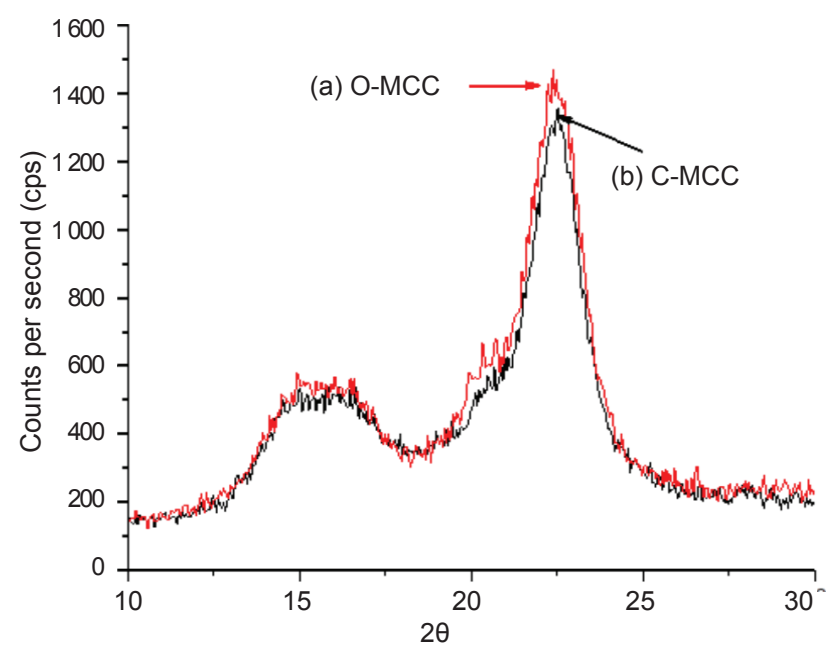

Figure 3. The X-ray diffractograms of (a) organosolv-microcrystalline cellulose (MCC) and (b) commercial-MCC.
As evident from DSC analysis (Figure 5), it was revealed that all the MCC samples boasthigher melting temperatures $\left(\mathrm{T}_{\mathrm{m}}\right)$ above $200^{\circ} \mathrm{C}$ since acid hydrolysis removes the hemicellulose content of MCC. The $\mathrm{T}_{\mathrm{m}}$ values for organosolv-MCC and commercial-MCC were found to be $223.15^{\circ} \mathrm{C}$ and $222.19^{\circ} \mathrm{C}$ respectively, associated with high thermal stability, indicative of a high degree of molecular ordering (Trache et al., 2016). In addition, the sharper peak observed for organosolv-MCC corresponds to higher crystallinity as evident from XRD analysis whereas commercialMCC depicted a broader peak due to the presence of higher content of amorphous cellulose, i.e., lower crystallinity. A recent research study carried out by Hussin et al. (2018) reported similar findings for organosolv-MCC and commercial-MCC.

BET analysis. The specific surface area of both commercial and extracted MCC was obtained from BET analysis of nitrogen adsorption, and the specific surface area of the MCC powders was estimated using BET equation. As listed in Table 4, the surface and pore properties of commercial and organosolv-MCC were compared. Organosolv-MCC demonstrated a higher BET surface area in comparison to commercialMCC upon acid hydrolysis, which can be attributed to the formation of porous cellulosic material (Trache et al., 2016). According to the average pore width

TABLE 4. SURFACE AND POROSITY PARAMETERS OF COMMERCIAL AND ORGANOSOLV MCC SAMPLES OBTAINED FROM BET ANALYSIS

\begin{tabular}{ccccc}
\hline Sample & $\begin{array}{c}\text { BET surface area } \\
\left(\mathbf{m}^{2} \mathbf{~}^{-1}\right)\end{array}$ & $\begin{array}{c}\text { Total pore volume } \\
\left(\mathrm{cm}^{3} \mathbf{g}^{-1}\right)\end{array}$ & $\begin{array}{c}\text { Cumulative pore volume } \\
\left(\mathrm{cm}^{3} \mathbf{~ g}^{-1}\right)\end{array}$ & $\begin{array}{c}\text { Average pore width } \\
(\mathbf{n m})\end{array}$ \\
\hline Organosolv-MCC & 10.10 & 0.0051 & 0.0041 & 2.02 \\
Commercial-MCC & 4.47 & 0.0038 & 0.0038 & 3.45 \\
\hline
\end{tabular}

Note: MCC- microcrystalline cellulose.

BET- Brunauer-Emmett-Teller.

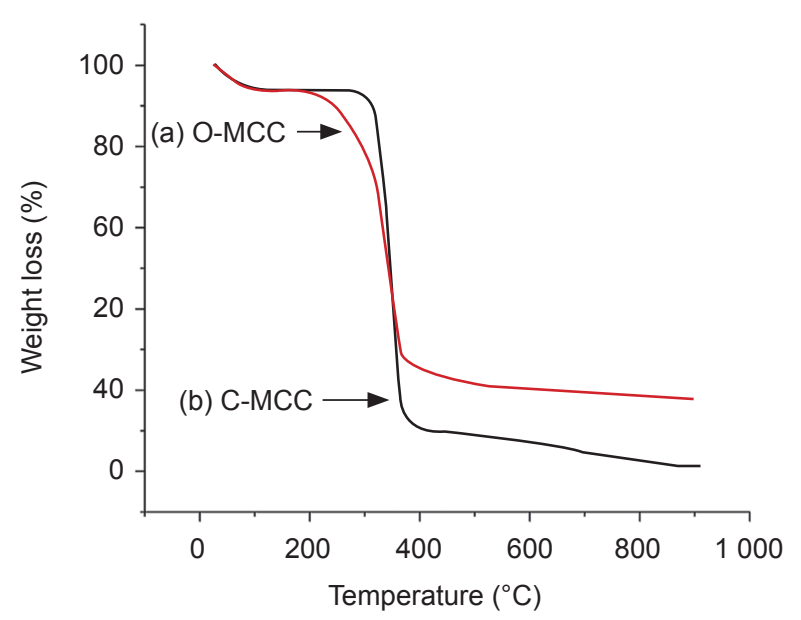

Figure 4. Thermogravimetric analysis (TGA) curves of (a) organosolvmicrocrystalline cellulose (MCC) and (b) commercial-MCC.

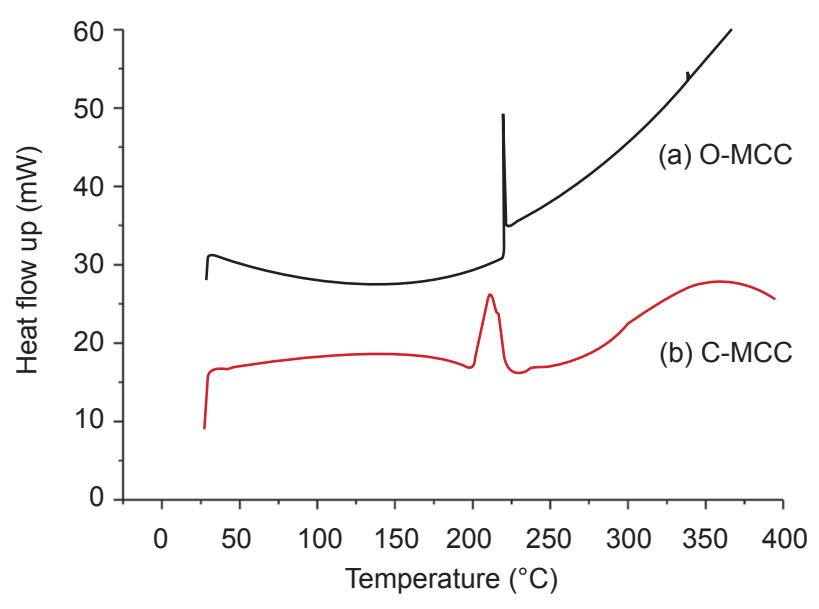

Figure 5. Differential scanning calorimetry (DSC) thermograms of (a) organosolv-microcrystalline cellulose (MCC) and (b) commercial-MCC. 
(2.02 nm), organosolv-MCC can be classified as mesoporous (2-50 $\mathrm{nm}$ diameter) on the International Union of Pure and Applied Chemistry (IUPAC) classification (Everett, 2009).

EIS analysis of MCC-PLA-LiTFSI polymer electrolyte. This work was devoted mainly to study the applicability of prepared polymer electrolytes consisting of MCC isolated from OPF as filler, PLA as the polymer matrix and LiTFSI as the conducting salt.

Polymer electrolyte films' ionic conductivities were studied using EIS at $30^{\circ} \mathrm{C}$. The bulk resistance $\left(R_{b}\right)$ of the polymer electrolytes can be obtained from the intercept of the high-frequency semi-circle or low-frequency spike on the $Z_{\text {real }}$ axis by fitting the EIS data using a suitable equivalent electrical circuit (Figure 6). EIS equivalent circuit obtained from ZSim Demo software was chosen based on the fact that it simulates closest to the prepared polymer electrolyte systems. Then, a non-linear least squares fitting program was used to fit the model to the experimental data which attempts to minimise the deviation between the spectrum of the model and the experimental data spectrum. In general, the fit algorithm will converge whenever the shape of the seed curve is similar to the shape of the data curve. The equivalent electrical circuit denotes a resistor $\left(R_{3}\right)$ in series with Warburg impedance $\left(\mathrm{W}_{4}\right)$ component wherein in parallel with constant phase element (ø). The $R_{3}$ represents the $R_{b}$ of the electrolyte, $W_{4}$ reflects the effect of the mass transport of the electroactive species on the total impedance of the electrochemical cell and $\varnothing$ denotes the capacitive nature of the electrolyte. Nyquist plots of polymer electrolytes consisting of MCC-PLA LiTFSI are depicted in Figure 7, while the ionic conductivities of polymer matrices are listed in Table 5. Usually, impedance plots obtained for polymer electrolytes comprise of two distinct regions. One is a high-frequency region (semi-circle) and the other one is a low-frequency region (spike). The high-frequency region depicts the bulk effect of the electrolytes while the low-frequency region represents the effect of blocking electrodes (Hemalatha et al., 2019). As apparent from Table 5, when the concentration of LiTFSI salt was raised to $20 \mathrm{wt} \%$, polymer electrolytes' ionic conductivity values kept increasing. The reason behind this could be related to the raised amount of $\mathrm{Li}^{+}$ions residing in the polymer composite and their movability along with the segmental polymer mobility (Tang et al., 2016).

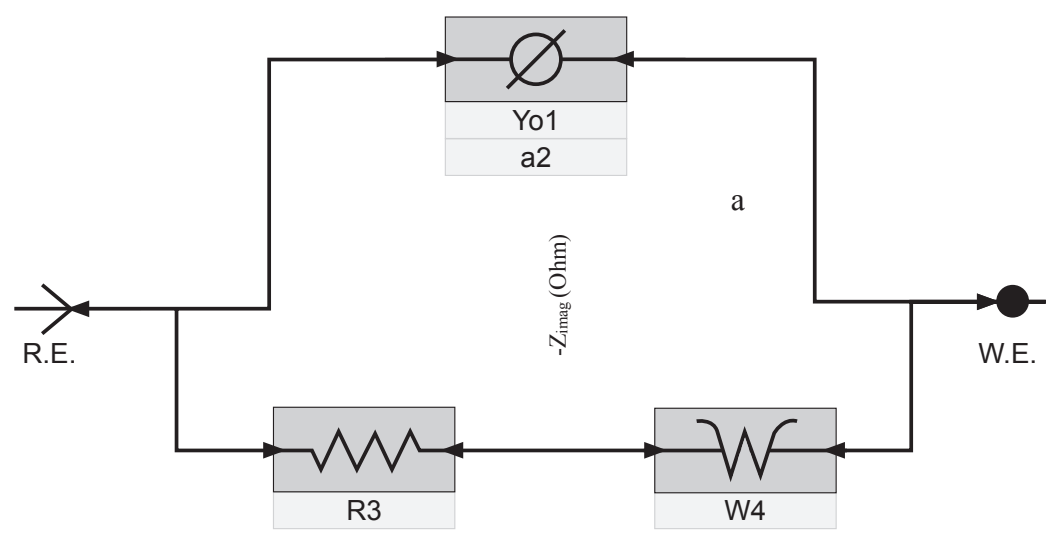

Figure 6. Equivalent electrical circuit used to fit electrochemical impedance spectroscopy (EIS) data.

(a)

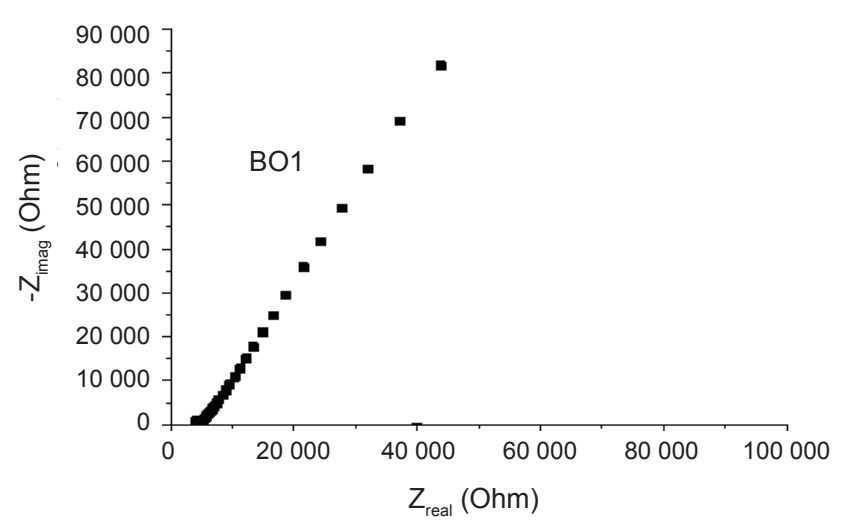

(b)

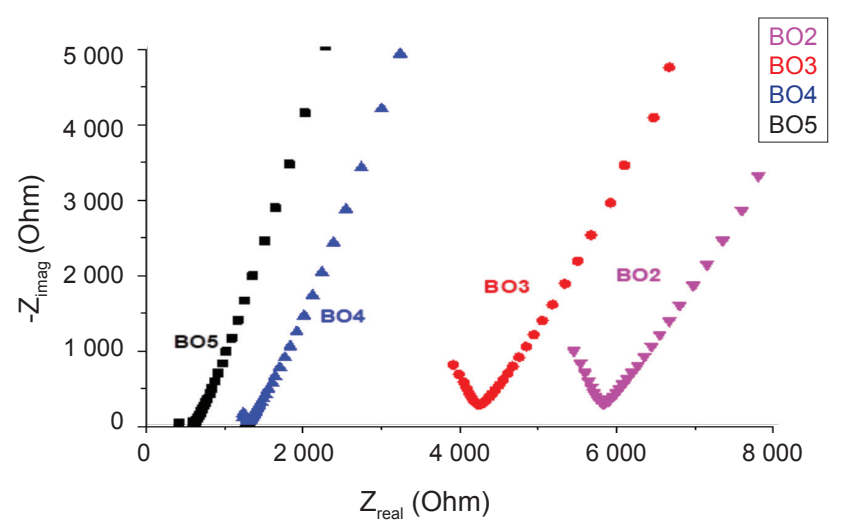

Figure 7. Nyquist plots of (a) $0 \%$ of lithium bis(trifluoromethanesulfonyl)imide (LiTFSI) in organosolv-microcrystalline cellulose (MCC)-polylactic acid (PLA) and (b) different percentages $(5,10,15,20 w t \%)$ of LiTFSI in organosolv-MCC-PLA. 
TABLE 5. THE PARAMETERS OF IONIC CONDUCTIVITY FOR COMPOSITE POLYMER OF THE ORGANOSOLV-MCC-PLA-LiTFSI

\begin{tabular}{|c|c|c|c|}
\hline Sample & $\begin{array}{c}\text { Thickness, } \times 10^{-3} \\
(\mathrm{~cm})\end{array}$ & $\begin{array}{l}R_{b r} \times 10^{3} \\
\left(\Omega \mathrm{cm}^{2}\right)\end{array}$ & $\begin{array}{l}\text { Conductivity } \\
\qquad\left(\mathrm{S} \mathrm{cm}^{-1}\right)\end{array}$ \\
\hline BO1 (OMCC-PLA- 0 wt\% LiTFSI) & 173.0 & 42.90 & $8.21 \times 10^{-10}$ \\
\hline BO2 (OMCC-PLA-5 wt\% LiTFSI) & 192.0 & 1.61 & $2.42 \times 10^{-9}$ \\
\hline BO3 (OMCC-PLA-10 wt\% LiTFSI) & 77.0 & 909.00 & $1.73 \times 10^{-8}$ \\
\hline BO4 (OMCC-PLA-15 wt\% LiTFSI) & 49.0 & 271.00 & $3.68 \times 10^{-7}$ \\
\hline BO5 (OMCC-PLA-20 wt\% LiTFSI) & 87.0 & 14.20 & $1.25 \times 10^{-5}$ \\
\hline PEO-PMMA-LiTFSI- $\mathrm{Al}_{2} \mathrm{O}_{3}$ (Liang et al., 2015) & NA & NA & $9.39 \times 10^{-7}$ \\
\hline OMCC-PVA-20 wt\% $\mathrm{LiClO}_{4}$ (Hussin et al., 2018) & 64.0 & 1.70 & $1.88 \times 10^{-4}$ \\
\hline PLA-ethylene carbonate- $20 \mathrm{wt} \%$ of $\mathrm{LiClO}_{4}$ (Chew et al., 2013) & NA & NA & $1.44 \times 10^{-6}$ \\
\hline Carboxy methylcellulose-7 wt $\% \mathrm{NH}_{4} \mathrm{CO}_{3}$ (Sohaimy and Isa, 2015) & NA & NA & $7.71 \times 10^{-6}$ \\
\hline
\end{tabular}

Note: OMCC - organosolv-microcrystalline cellulose.

PLA - polylactic acid.

LiTFSI - lithium bis(trifluoromethanesulfonyl)imide.

PMMA - polymethyl methacrylate.

PVA - polyvinyl alcohol.

NA - not available.

Polymer electrolyte film from organosolv-MCC filler displayed an optimum ionic conductivity; 1.25 $x 10^{-5} \mathrm{~S} \mathrm{~cm}^{-1}$ for BO5 film (organosolv-MCC-PLA-20 wt $\%$ LiTFSI). The ionic conductivity exhibited by organosolv-MCC filled polymer electrolytes is strongly related to low molecular weight, high degree of crystallinity index and better porosity of organosolv-MCC could be the main factors that contribute to better conduction by accelerating the mobility of $\mathrm{Li}^{+}$ions as such this increases the movement of ions inside the polymer electrolytes (Figure 8). As depicted in Figure 8, $\mathrm{Li}^{+}$ions can be coordinated through the lone pairs of electrons of the oxygen atoms on a segment of PLA chain. Through the processes of bond breaking/forming of $\mathrm{Li}-\mathrm{O}$, ion transport can occur via interchain hopping (Xue et al., 2015) in the PVA-based polymer matrix. Figure 8 illustrates the hopping mechanism where $\mathrm{Li}^{+}$ 'jump/ hop' from one coordination site into an empty neighbouring one. High mobility of mobile ions $\left(\mathrm{Li}^{+}\right.$ and $\mathrm{TFSI}^{-}$) can be correlated to the low activation energy for ionic motion from site to site. Since TFSI ${ }^{-}$ is a strong electron-withdrawing group with flexible nitrogen covalent bonding, LiTFSI salt could readily be dissociated in the polymer composite to provide more pathways for the polymer chains to move (Zhang et al., 2013). Moreover, researchers have demonstrated the distribution of nano/micro sized fillers particles in solid polymer electrolyte hosts which enhance SPE membranes' electrochemical, structural and mechanical properties (Appetecchi et al., 2000).

Table 5 depicts a comparison of ionic conductivities between the previous studies and the present study. Chew (2014) reported an ionic conductivity value of $3.6 \times 10^{-12} \mathrm{~S} \mathrm{~cm}^{-1}$ for pure PLA which showed that PLA is an insulator since it is highly crystalline whereas the ionic conductivity of pure PVA is $5.9 \times 10^{-10} \mathrm{~S} \mathrm{~cm}^{-1}$ (Mohamad et al., 2003). Rosol et al. (2009) compared the ionic conductivities of $\mathrm{LiClO}_{4}$ and LiTFSI salts in 1-butyl-3-methylimidazolium-thiocyanate [BMIM]SCN ionic liquid at the temperature range of $25^{\circ} \mathrm{C}$ to $75^{\circ} \mathrm{C}$. According to the data obtained, it was affirmed that the incorporation of $\mathrm{LiClO}_{4}$ resulted in higher ionic conductivity compared to the addition of LiTFSI. It was further noted that the nature of the anion of $\mathrm{Li}$ salts makes a significant effect in the solubilisation of lithium salts. The recent research study (Hussin et al., 2018) achieved a higher optimum ionic conductivity for OMCC-PVA- $\mathrm{LiClO}_{4}$ polymer electrolyte compared to OMCC-PLA-LiTFSI polymer electrolyte prepared in the present study due to the fact of utilising different polymer matrices and lithium salts which leads to a variation in ionic conductivity values. Also, it is evident that the ionic salt is the main contributor to ionic conductivity.

Effect of 5 wt\% BMIMCl ionic liquid. The optimised polymer electrolyte film was used to investigate the ionic conductivity effect of $\mathrm{BMIMCl}$ ionic liquid upon its addition. According to the results presented in Figure 9, it was revealed that the $\mathrm{BO} 5$ polymer electrolyte with the addition of $5 \mathrm{wt} \% \mathrm{BMIMCl}$ ionic liquid exhibited an even higher ionic conductivity $\left(2.3 \times 10^{-5} \mathrm{~S} \mathrm{~cm}^{-1}\right)$. Therefore, application of BMIMCl ionic liquid on the polymer electrolyte is beneficial to reduce the aggregation and adhesion of $\mathrm{Li}^{+}$salt by making their mobility in polymer membrane more effective, thus, improving polymer electrolyte's ionic conductivity since it promotes better ionic transports in the polymer membrane (Chew et al., 2013). Kumar et al. (2011) suggested that BMIM ${ }^{+}$ion generates free volume for ionic conduction, which increases the ionic conductivity of the polymer electrolyte. 
Characterisation of organosolv-MCC-PLA-20 $w t \%$ LiTFSI polymer electrolyte. FT-IR plots of PLA, LiTFSI and BO5 are displayed in Figure 10. For pure PLA, the assignments accord with Karande et al. (2015) findings. Intense hydroxyl peak observed ca. $3467 \mathrm{~cm}^{-1}$ depicted $\mathrm{OH}$ groups' stretching, while the strong band observed at $2995 \mathrm{~cm}^{-1}$ denotes stretching IR peaks of methyl and methylene C-H. The $1143 \mathrm{~cm}^{-1}$ IR peak was assigned as C-O alcoholic stretching. A band corresponding to $\mathrm{C}-\mathrm{H}$ bending is positioned at around $1331 \mathrm{~cm}^{-1}$. The presence of strong absorption at $1757 \mathrm{~cm}^{-1}$ corresponds to $\mathrm{C}=\mathrm{O}$ stretching vibration. Meanwhile, the FT-IR spectrum of LiTFSI shows resemblance to that documented by Kam et al. (2014), the first peak corresponding to $\mathrm{N}-\mathrm{SO}_{2}-\mathrm{C}$ vibration of LiTFSI is positioned at $1144 \mathrm{~cm}^{-1}$. Two of the characteristic low intense signals located at 798 and $741 \mathrm{~cm}^{-1}$ illustrates bending (symmetric) of $\mathrm{CF}_{3}$ and stretching vibration of S-N, respectively (Kam et al., 2014).

As for BO5 (organosolv-MCC-PLA-20 wt\% LiTFSI) polymer electrolyte, it was clear that the spectrum resembles the combination of PLA, MCC and LiTFSI spectra without the formation of a new peak. This justifies that blending does not alter the individual characteristic of the respective materials. When PLA was encapsulated with LiTFSI, a shift in signal was detected at around $1759 \mathrm{~cm}^{-1}$, probably due to newly formed coordination bond among the polymer matrix and $\mathrm{Li}^{+}$ion, occurring at carbonyl group's oxygen atom of PLA (Ramesh et al., 2007).
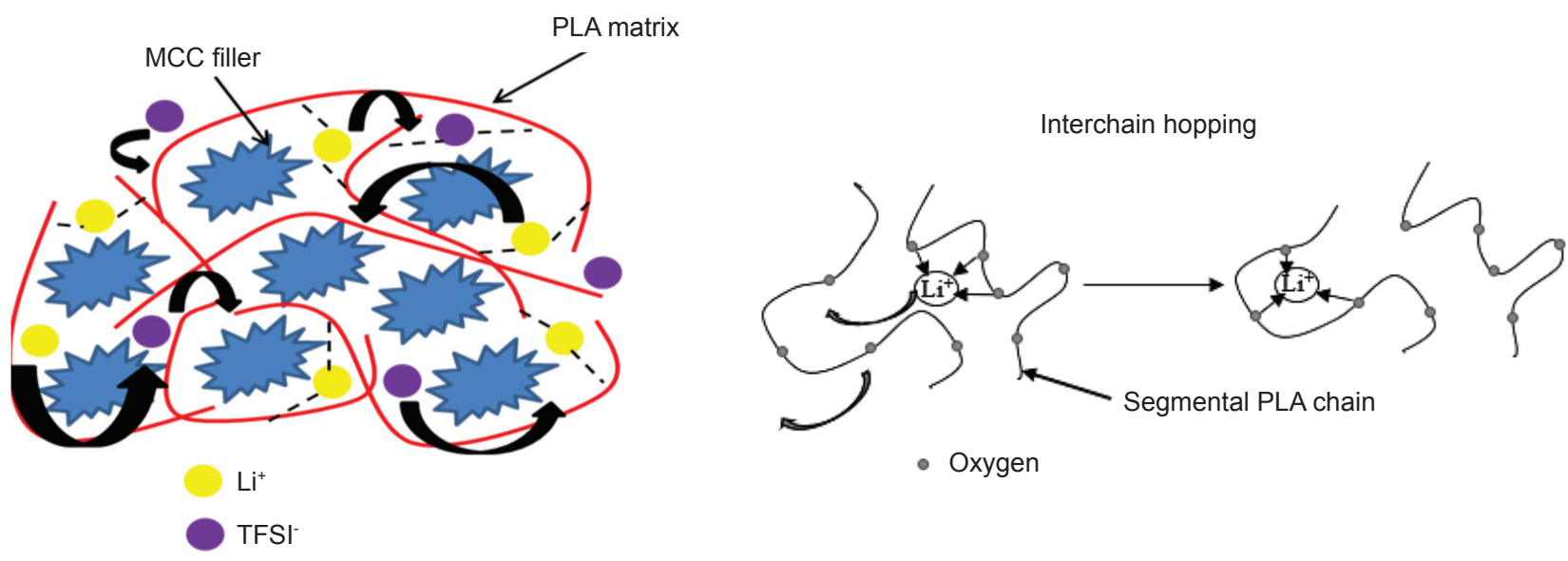

Figure 8. Proposed ion transport mechanism of microcrystalline cellulose (MCC)-polylactic acid (PLA)-lithium bis(trifluoromethanesulfonyl)imide (LiTFSI) polymer electrolyte.

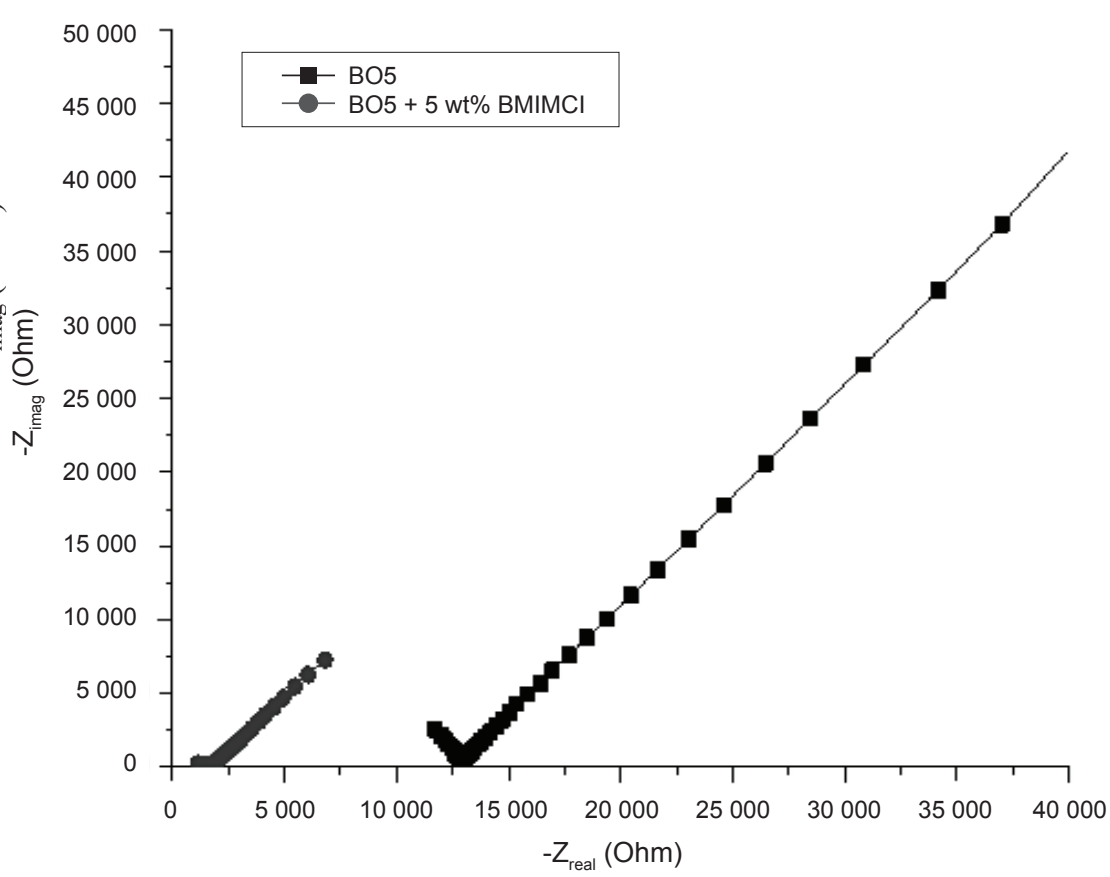

Figure 9. Nyquist plots of BO5 [OMCC-polylactic acid (PLA)]-20 wt\% lithium bis(trifluoromethanesulfonyl)imide (LiTFSI) films with and without addition of 5 wt\% 1-butyl-3-methylimidazolium chloride (BMIMCl). 


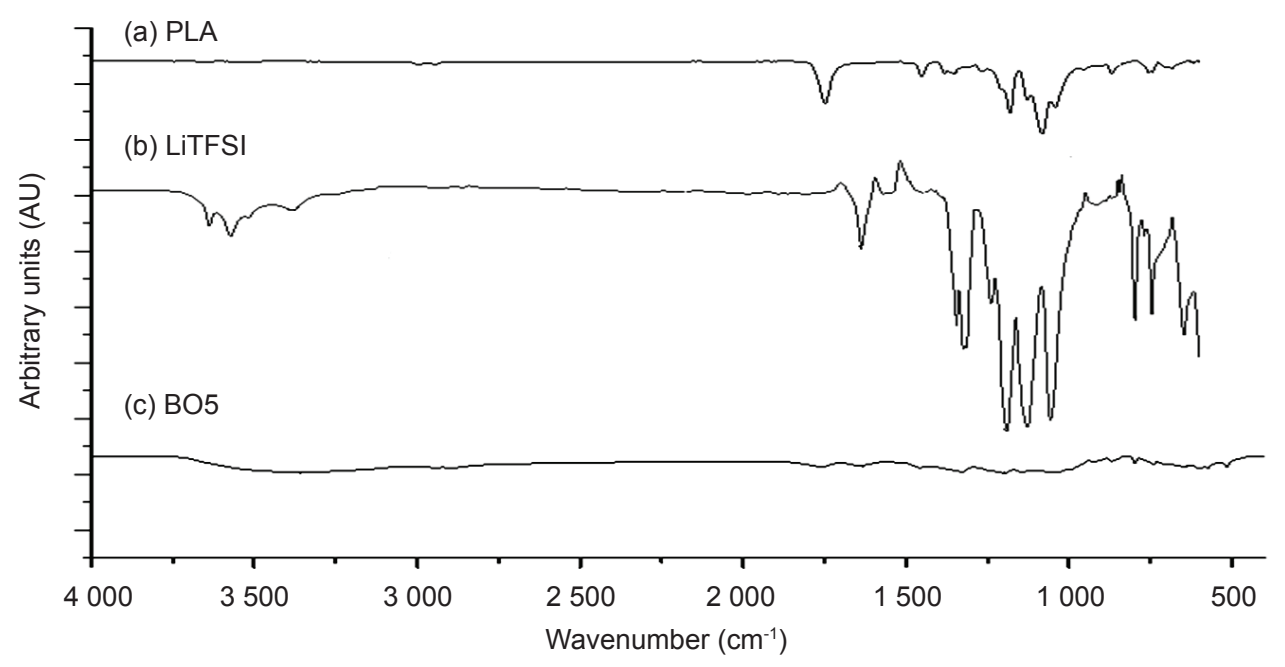

Figure 10. Fourier transform infrared spectroscopy (FT-IR) spectra for (a) pure polylactic acid (PLA), (b) pure lithium bis(trifluoromethanesulfonyl)imide (LiTFSI), and (c) BO5 (OMCC-PLA-20 wt\% LiTFSI).

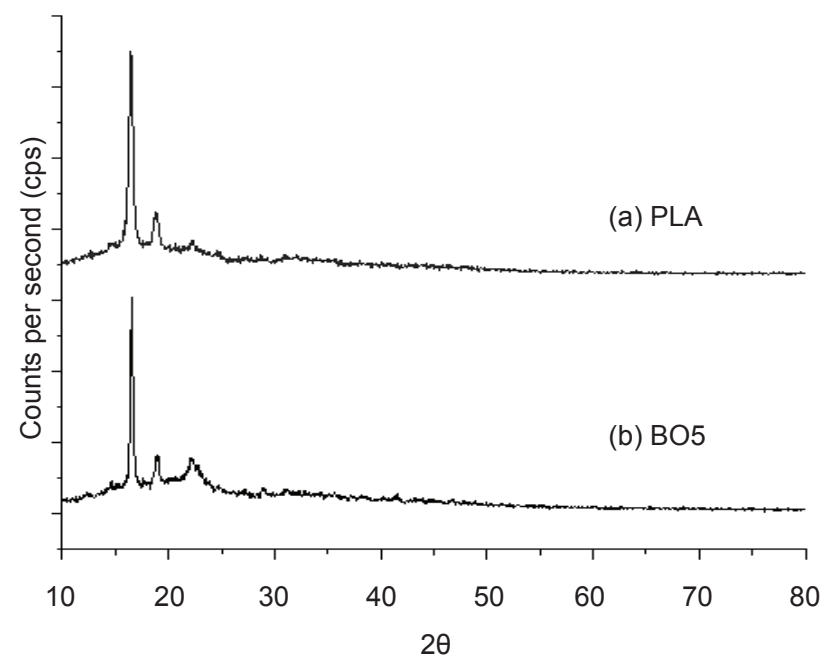

Figure 11. The X-ray diffractograms of (a) pure polylactic acid (PLA), and (b) BO5 organosolv-microcrystalline cellulose-polylactic acid-20 wt\% lithium bis(trifluoromethanesulfonyl)imide (OMCC-PLA-20 wt\% LiTFSI).

Figure 11 shows the XRD diffractograms of pure PLA and BO5 (organosolv-MCC-PLA-20 wt\% LiTFSI) polymer electrolyte. From Figure 11, a wide distinctive signal of pure PLA was identified at $2 \theta=17.02^{\circ}, 19.30^{\circ}$ and $29.90^{\circ}$, which affirms the presence of crystalline phase of PLA (Tang et al., 2016). Meanwhile, the diffractogram of BO5 (organosolv-MCC-PLA-20 wt $\%$ LiTFSI) shows a similar pattern with pure PLA in the presence of MCC peaks $\left(2 \theta=18.0^{\circ}\right.$ and $\left.22.0^{\circ}\right)$. Previous studies indicated that the LiTFSI should show sharp peaks at $2 \theta=13.60^{\circ}, 15.9^{\circ}, 18.9^{\circ}$ and $21.4^{\circ}$, which narrates the crystalline properties of LiTFSI. However, from this study, it was observed that these crystalline peaks were suppressed in the organosolv-MCC-PLA-LiTFSI polymer electrolyte. The absence of excess salt could indicate that it complexes with the polymer host (Rajendran et al., 2004). Furthermore, because LiTFSI salt getting dissolved thoroughly in the polymer electrolyte system, could also

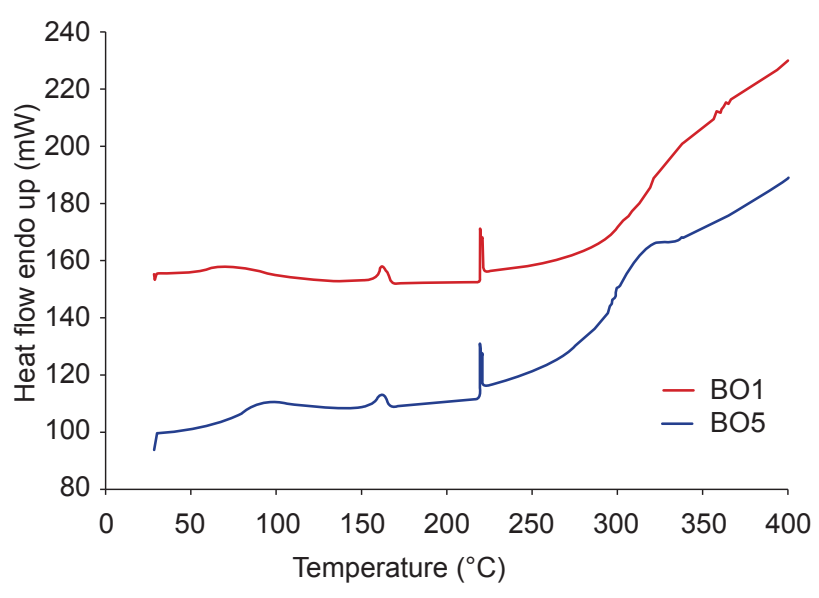

Figure 12. Differential scanning calorimetry (DSC) thermograms of BO1 organosolv-microcrystalline cellulose-polylactic acid-0 wt\% lithium bis(trifluoromethanesulfonyl)imide (OMCC-PLA-0 wt\% LiTFSI), and BO5 (OMCC-PLA-20 wt\% LiTFSI).

direct to a strong complexing of the polymer host with the salt (Baskaran et al., 2006).

The DSC thermograms of BO1 (organosolvMCC-PLA-0 wt\% LiTFSI) and BO5 (organosolvMCC-PLA-20 wt\% LiTFSI) are shown in Figure 12. DSC thermograms depicted an endothermic peak $\left(\mathrm{T}_{\mathrm{g}}\right)$, followed by $\mathrm{T}_{\mathrm{m}}$ and $\mathrm{T}_{\mathrm{d}}$ with further heating of the samples. According to Figure 12, $\mathrm{T}_{\mathrm{g}}$ increased with the addition of LiTFSI $\left(\mathrm{T}_{\mathrm{g} \mathrm{BO5}} 81.69^{\circ} \mathrm{C}>\mathrm{T}_{\mathrm{g} \text { вO1 }}\right.$ $68.70^{\circ} \mathrm{C}$ ). Increment observed in $\mathrm{T}_{\mathrm{g}}$ for $\mathrm{BO} 5$ could be due to the more preferential interaction of $\mathrm{Li}^{+}$ with electron dense coordinating groups (e.g., O-) through transient cross-linkage bonds, which hinder the circling of polymer moiety. Thus, the flexibility of polymer backbone gets reduced due to this $\mathrm{Li}^{+}-\mathrm{O}^{-}$ bonding (Ramesh and Arof, 2001). Additionally, two distinct endothermic peaks, $\mathrm{T}_{\mathrm{m}}$ are illustrated in Figure 2. These peaks were due to the melting points of PLA $\left(\sim 150^{\circ} \mathrm{C}\right)$ and $\mathrm{MCC}\left(\sim 220^{\circ} \mathrm{C}\right)$, while the endothermic peak representing $\mathrm{MCC}$ is called decomposition temperature $\left(\mathrm{T}_{\mathrm{d}}\right)$. 


\section{CONCLUSION}

Current research study brought to light that MCC has potential applications especially in Li-ion battery performance enhancement, supercapacitors, flexible and biodegradable conductive materials by forming complexes with the polymer host. The mechanism of formation of the complex among the polymer matrix and $\mathrm{Li}^{+}$occur at the carbonyl group's oxygen atom. DSC and TGA analyses demonstrated the high thermal stability of organosolv-MCC after acid hydrolysis. Based on X-ray diffraction analysis, organosolv-MCC obtained belonging to OPF was indexed cellulose type I $\left(22.0^{\circ}, 002\right.$ lattice planes). Nitrogen adsorption analysis of the organosolv-MCC showed that it has a higher specific surface area $\left(\mathrm{S}_{\mathrm{BET}}\right)$ and a more significant pore volume. The impedance analysis of the prepared film electrolyte displayed an increase in conductivity when increasing the salt concentration. An optimum conductivity of $1.25 \mathrm{x}$ $10^{-5} \mathrm{~S} \mathrm{~cm}^{-1}$ was gained for BO5 (20\% OrganosolvMCC-60\% PLA-20 wt $\%$ LiTFSI), while 5 wt $\%$ $\mathrm{BMIMCl}$ ionic liquid added had a positive effect on polymer electrolyte's ionic conductivity resulting in a higher conductivity of $2.3 \times 10^{-5} \mathrm{~S} \mathrm{~cm}^{-1}$.

\section{ACKNOWLEDGEMENT}

This research study was funded by the Universiti Sains Malaysia through USM Research University Incentive Grant (1001/PKIMIA/8011077). Tuan Sherwyn Hamidon wishes to extend his profound acknowledgement to Universiti Sains Malaysia for the financial assistance through USM Graduate Assistant Scheme.

\section{REFERENCES}

Adel, A M; Abd El-Wahab, Z H; Ibrahim, A A and Al-Shemy, M T (2011). Characterization of microcrystalline cellulose prepared from lignocellulosic materials. Part II: Physicochemical properties. Carbohyd. Polym., 83(2): 676-687.

Adel, A M; El-Wahab, Z H A; Ibrahim, A A and Al-Shemy, M T (2010). Characterization of microcrystalline cellulose prepared from lignocellulosic materials. Part I. Acid catalyzed hydrolysis. Bioresource Technol., 101(12): 4446-4455.

Appetecchi, G; Scaccia, S and Passerini, S (2000). Investigation on the stability of the lithium-polymer electrolyte interface. J. Electrochem. Soc., 147(12): 4448-4452.

Azubuike, C P and Okhamafe, A O (2012). Physicochemical, spectroscopic and thermal properties of microcrystalline cellulose derived from corn cobs. Int. J. Recycl. Org. Waste Agricult., 1(1): $72-78$.

Baskaran, R; Selvasekarapandian, S; Kuwata, N; Kawamura, J and Hattori, T (2006). Conductivity and thermal studies of blend polymer electrolytes based on PVAc-PMMA. Solid State Ionics, 177(26): 2679-2682.

Bhat, S and Kumar, A (2013). Biomaterials and bioengineering tomorrow's healthcare. Biomatter, 3(3): e24717.

Brosse, N; Hussin, M H and Rahim, A A (2017). Organosolv processes. Advances in Biochemical Engineering/Biotechnology. Springer, Berlin, Heidelberg. p. 1-24.

Chauhan, Y P; Sapkal, R S; Sapkal, V S and Zamre, G S (2009). Microcrystalline cellulose from cotton rags (waste from garment and hosiery industries). Int. J. Chem. Sci., 7(2): 681-688.

Chew, K W (2014). Development of novel biodegradable electrolyte based on polylactide (PLA) for lithium rechargeable battery. Adv. Mater. Res., 853: $270-275$.

Chew, K W; Ng, T C and How, Z H (2013). Conductivity and microstructure study of PLAbased polymer electrolyte salted with lithium perchloride, $\mathrm{LiClO}_{4}$. Int. J. Electrochem. Sci., 8(5): 6354-6364.

Chunilall, V; Bush, T and Larsson, P T (2013). Supra-molecular structure and chemical reactivity of cellulose I studied using CP/MAS ${ }^{13} \mathrm{C}-\mathrm{NMR}$. Cellulose-Fundamental Aspects (Ven, T V D and Godbout, L eds.). InTech, Rijeka. p. 69-90.

Diakité, M; Paul, A; Jäger, C; Pielert, J and Mumme, J (2013). Chemical and morphological changes in hydrochars derived from microcrystalline cellulose and investigated by chromatographic, spectroscopic and adsorption techniques. Bioresource Technol., 150: 98-105.

El Hage, R; Brosse, N; Chrusciel, L; Sanchez, C; Sannigrahi, P and Ragauskas, A (2009). Characterization of milled wood lignin and ethanol organosolv lignin from miscanthus. Polym. Degrad. Stabil., 94(10): 1632-1638.

Elanthikkal, S; Gopalakrishnapanicker, U; Varghese, S and Guthrie, J T (2010). Cellulose microfibres produced from banana plant wastes: Isolation and characterization. Carbohyd. Polym., 80(3): 852-859. 
Engel, P; Hein, L and Spiess, A C (2012). Derivatization-free gel permeation chromatography elucidates enzymatic cellulose hydrolysis. Biotechnol. Biofuels, 5(1): 77.

Everett, D H (2009). Manual of symbols and terminology for physicochemical quantities and units. Appendix II: Definitions, terminology and symbols in colloid and surface chemistry. Pure. Appl. Chem., 31(4): 577-638.

Foston, M B; Hubbell, C A and Ragauskas, A J (2011). Cellulose isolation methodology for NMR analysis of cellulose ultrastructure. Materials Vol. 4 (11): 19852002.

Gonzalez-Rivera, J; Galindo-Esquivel, I R; Onor, M; Bramanti, E; Longo, I and Ferrari, C (2014). Heterogeneous catalytic reaction of microcrystalline cellulose in hydrothermal microwave-assisted decomposition: Effect of modified zeolite Beta. Green Chem., 16(3): 1417-1425.

Haafiz, M K M; Hassan, A; Zakaria, Z and Inuwa, I M (2014). Isolation and characterization of cellulose nanowhiskers from oil palm biomass microcrystalline cellulose. Carbohyd. Polym., 103: 119-125.

Hamad, W Y (2013). Cellulosic Materials: Fibers, Networks and Composites. Springer Science and Business Media. Dordrecht, The Netherlands. 198 pp.

Hemalatha, R; Alagar, M; Selvasekarapandian, S; Sundaresan, B; Moniha, V; Boopathi, G and Selvin, P $C$ (2019). Preparation and characterization of protonconducting polymer electrolyte based on PVA, amino acid proline, and $\mathrm{NH}_{4} \mathrm{Cl}$ and its applications to electrochemical devices. Ionics, 25(1): 141-154.

Hussin, M H; Husin, N A; Bello, I; Othman, N; Bakar, M A and Haafiz, M M (2018). Isolation of microcrystalline cellulose (MCC) from oil palm frond as potential natural filler for $\mathrm{PVA}-\mathrm{LiClO}_{4}$ polymer electrolyte. Int. J. Electrochem. Sci., 13: 3356-3371.

Hussin, M H; Pohan, N A; Garba, Z N; Kassim, M J; Rahim, A A; Brosse, N; Yemloul, M; Fazita, M R N and Haafiz, M K M (2016). Physicochemical of microcrystalline cellulose from oil palm fronds as potential methylene blue adsorbents. Int. J. Biol. Macromol., 92: 11-19.

Hussin, M H; Rahim, A A; Mohamad Ibrahim, M N and Brosse, N (2013). Physicochemical characterization of alkaline and ethanol organosolv lignins from oil palm (Elaeis guineensis) fronds as phenol substitutes for green material applications. Ind. Crop. Prod., 49: 23-32.
Jonoobi, M; Khazaeian, A; Tahir, P M; Azry, S S and Oksman, K (2011). Characteristics of cellulose nanofibers isolated from rubberwood and empty fruit bunches of oil palm using chemo-mechanical process. Cellulose, 18(4): 1085-1095.

Kalita, RD; Nath, Y; Ochubiojo, ME and Buragohain, A K (2013). Extraction and characterization of microcrystalline cellulose from fodder grass; Setaria glauca (L) P. Beauv, and its potential as a drug delivery vehicle for isoniazid, a first line antituberculosis drug. Colloid. Surface. B., 108: 85-89.

Kam, W; Liew, C W; Lim, J Y and Ramesh, S (2014). Electrical, structural, and thermal studies of antimony trioxide-doped poly(acrylic acid)-based composite polymer electrolytes. Ionics, 20(5): 665674.

Karande, R D; Abitha, V K; Rane, A V and Mishra, R K (2015). Preparation of polylactide from synthesized lactic acid and effect of reaction parameters on conversion. J. Mater. Sci. Eng. Adv. Technol., 12(1-2): $1-37$.

Khiar, A S A and Arof, A K (2010). Conductivity studies of starch-based polymer electrolytes. Ionics, 16(2): 123-129.

Kiziltas, A; Gardner, DJ; Han, Y and Yang, HS (2010). Thermal properties of microcrystalline cellulosefilled PET-PTT blend polymer composites. J. Therm. Anal. Calorim., 103(1): 163-170.

Kumar, Y; Hashmi, S A and Pandey, G P (2011). Lithium ion transport and ion-polymer interaction in PEO based polymer electrolyte plasticized with ionic liquid. Solid State Ionics, 201(1): 73-80.

Li, R; Fei, J; Cai, Y; Li, Y; Feng, J and Yao, J (2009). Cellulose whiskers extracted from mulberry: A novel biomass production. Carbohyd. Polym., 76(1): 94-99.

Liang, B; Tang, S; Jiang, Q; Chen, C; Chen, X; Li, S and Yan, $X$ (2015). Preparation and characterization of PEO-PMMA polymer composite electrolytes doped with nano- $\mathrm{Al}_{2} \mathrm{O}_{3}$. Electrochim. Acta, 169: 334341.

Mathew, A P; Oksman, K and Sain, M (2005). Mechanical properties of biodegradable composites from poly lactic acid (PLA) and microcrystalline cellulose (MCC). J. Appl. Polym. Sci., 97(5): 2014-2025.

Merci, A; Urbano, A; Grossmann, M V E; Tischer, C A and Mali, S (2015). Properties of microcrystalline cellulose extracted from soybean hulls by reactive extrusion. Food Res. Int., 73: 38-43. 
Miao, C and Hamad, W Y (2013). Cellulose reinforced polymer composites and nanocomposites: A critical review. Cellulose, 20(5): 2221-2262.

Miura, K and Nakano, T (2016). Analysis of the effects of restriction of longitudinal contraction on the conversion from cellulose I to cellulose II using $\mathrm{CP} / \mathrm{MAS}{ }^{13} \mathrm{C}$ NMR: Mercerization of ramie fibers under noncooling and cooling conditions. J. Mater. Sci., 51(13): 6331-6340.

Mohamad, A A; Mohamed, N S; Yahya, M Z A; Othman, R; Ramesh, S; Alias, Y and Arof, A K (2003). Ionic conductivity studies of poly(vinyl alcohol) alkaline solid polymer electrolyte and its use in nickel-zinc cells. Solid State Ionics, 156(1): 171-177.

Mohamad Haafiz, M K; Eichhorn, S J; Hassan, A and Jawaid, M (2013a). Isolation and characterization of microcrystalline cellulose from oil palm biomass residue. Carbohyd. Polym., 93(2): 628-634.

Mohamad Haafiz, M K; Hassan, A; Zakaria, Z; Inuwa, I M; Islam, M S and Jawaid, M (2013b). Properties of polylactic acid composites reinforced with oil palm biomass microcrystalline cellulose. Carbohyd. Polym., 98(1): 139-145.

Nakagaito, A N; Fujimura, A; Sakai, T; Hama, Y and Yano, H (2009). Production of microfibrillated cellulose (MFC)-reinforced polylactic acid (PLA) nanocomposites from sheets obtained by a papermaking-like process. Compos. Sci. Technol., 69(7): 1293-1297.

Narayanan, R and Laine, R M (1997). Synthesis and characterization of precursors for group II metal aluminates. Appl. Organomet. Chem., 11: 919-927.

Newman, R H and Hemmingson, J A (1995). Carbon-13 NMR distinction between categories of molecular order and disorder in cellulose. Cellulose, 2(2): 95-110.

Oksman, K; Mathew, A P; Bondeson, D and Kvien, I (2006). Manufacturing process of cellulose whiskers/polylactic acid nanocomposites. Compos. Sci. Technol., 66(15): 2776-2784.

Rajendran, S; Sivakumar, M and Subadevi, R (2004). Investigations on the effect of various plasticizers in PVA-PMMA solid polymer blend electrolytes. Mater. Lett., 58(5): 641-649.

Ramayya, A P; Chakraborty, S K and De, S K (1984). Studies on replacement of silica by carbon black in the tricomponent dry bonding system of short fiberrubber composites. J. Appl. Polym. Sci., 29(5): 19111917.
Ramesh, S and Arof, A K (2001). Structural, thermal and electrochemical cell characteristics of poly(vinyl chloride)-based polymer electrolytes. J. Power Sources, 99(1): 41-47.

Ramesh, S; Leen, K H; Kumutha, K and Arof, A K (2007). FTIR studies of PVC/PMMA blend based polymer electrolytes. Spectrochim. Acta A., 66(4): 1237-1242.

Ramesh, S; Yuen, T F and Shen, C J (2008). Conductivity and FTIR studies on PEO-LiX [X: $\left.\mathrm{CF}_{3} \mathrm{SO}_{3}{ }^{-}, \mathrm{SO}_{4}{ }^{2-}\right]$ polymer electrolytes. Spectrochim. Acta A., 69(2): 670-675.

Rathod, S G; Bhajantri, R F; Ravindrachary, V; Pujari, P K; Nagaraja, G K; Naik, J; Hebbar, V and Chandrappa, H (2015). Temperature-dependent ionic conductivity and transport properties of $\mathrm{LiClO}_{4}$-doped PVA/modified cellulose composites. B. Mater. Sci., 38(5): 1213-1221.

Rhim, J W (2007). Potential use of biopolymerbased nanocomposite films in food packaging applications. Food Sci. Biotechnol., 16(5): 691-709.

Rosol, Z P; German, N J and Gross, S M (2009). Solubility, ionic conductivity and viscosity of lithium salts in room temperature ionic liquids. Green Chem., 11(9): 1453-1457.

Sanchez-Garcia, M D and Lagaron, J M (2010). On the use of plant cellulose nanowhiskers to enhance the barrier properties of polylactic acid. Cellulose, 17(5): 987-1004.

Segal, L; Creely, J J; A E; Martin, J and Conrad, C $M$ (1959). An empirical method for estimating the degree of crystallinity of native cellulose using the X-ray diffractometer. Text. Res. J., 29(10): 786-794.

Shin, J H; Henderson, W A and Passerini, S (2003). Ionic liquids to the rescue? Overcoming the ionic conductivity limitations of polymer electrolytes. Electrochem. Commun., 5(12): 1016-1020.

Sohaimy, M I H and Isa, M I N (2015). Conductivity and dielectric analysis of cellulose based solid polymer electrolytes doped with ammonium carbonate $\left(\mathrm{NH}_{4} \mathrm{CO}_{3}\right)$. Appl. Mech. Mater., 719: 67-72.

Song, J; Ge, H; Xu, M; Chen, Q and Zhang, L (2014). Study on the interaction between urea and cellulose by combining solid-state ${ }^{13} \mathrm{C} \mathrm{CP} / \mathrm{MAS} \mathrm{NMR}$ and extended Hückel charges. Cellulose, 21(6): 40194027.

Sudhakar, Y N and Selvakumar, M (2012). Lithium perchlorate doped plasticized chitosan and starch 
blend as biodegradable polymer electrolyte for supercapacitors. Electrochim. Acta., 78: 398-405.

Tang, J; Muchakayala, R; Song, S; Wang, M and Kumar, K N (2016). Effect of EMIMBF ${ }_{4}$ ionic liquid addition on the structure and ionic conductivity of $\mathrm{LiBF}_{4}$-complexed PVdF-HFP polymer electrolyte films. Polym. Test., 50: 247-254.

Teuber, L; Osburg, V S; Toporowski, W; Militz, H and Krause, A (2016). Wood polymer composites and their contribution to cascading utilisation. J. Clean. Prod., 110: 9-15.

Thummanukitcharoen, P; Limpanart, S and Srikulkit, K (2012). Preparation of organosilane treated microcrystalline (SiMCC) and SiMCC/polypropylene composites. J. Met. Mater. Miner., 22(1): 13-19.

Tikhonov, N A; Arkhangelsky, I V; Belyaev, S S and Matveev, A T (2009). Carbonization of polymeric nonwoven materials. Thermochim. Acta., 486(1): 66-70.

Timilsena, Y P; Abeywickrama, C J; Rakshit, S K and Brosse, N (2013). Effect of different pretreatments on delignification pattern and enzymatic hydrolysability of miscanthus, oil palm biomass and typha grass. Bioresource Technol., 135: 82-88.

Trache, D; Donnot, A; Khimeche, K; Benelmir, R and Brosse, N (2014). Physico-chemical properties and thermal stability of microcrystalline cellulose isolated from Alfa fibres. Carbohyd. Polym., 104: 223-230.

Trache, D; Hussin, M H; Hui Chuin, C T; Sabar, S; Fazita, M R N; Taiwo, O F A; Hassan, T M and Haafiz, M K M (2016). Microcrystalline cellulose: Isolation, characterization and bio-composites application - A review. Int. J. Biol. Macromol., 93: 789-804.

Vroman, I and Tighzert, L (2009). Biodegradable polymers. Materials, 2(2): 307-344.

Wu, L M; Tong, D S; Zhao, L Z; Yu, W H; Zhou, C H and Wang, H (2014). Fourier transform infrared spectroscopy analysis for hydrothermal transformation of microcrystalline cellulose on montmorillonite. Appl. Clay Sci., 95: 74-82.

Xiuju, Z; Juncai, S; Huajun, Y; Zhidan, Land Shaozao, $T$ (2011). Mechanical properties, morphology, thermal performance, crystallization behavior, and kinetics of $\mathrm{pp} / \mathrm{microcrystal}$ cellulose composites compatibilized by two different compatibilizers. J. Thermoplast. Compos, 24(6): 735-754.

Xu, Y X; Kim, K M; Hanna, M A and Nag, D (2005). Chitosan-starch composite film: Preparation and characterization. Ind. Crop. Prod., 21(2): 185-192.

Xue, Z; He, D and Xie, X (2015). Poly(ethylene oxide)-based electrolytes for lithium-ion batteries. J. Mater. Chem. A. 3: 19218-19253.

Zhang, J; Cui, Y; Zhang, X; Sun, Q; Zheng, J; Wang, P; Feng, J and Zhu, Y (2013). LiTFSI as a plastic salt in the quasi-solid state polymer electrolyte for dye-sensitized solar cells. C. R. Chim., 16(2): 195200.

Zhu, X; Tan, L; Feng, G; Yang, J; Gao, Y and Dai, Y (2015). Research on degradation of cellulose using enzyme treatment in flue-cured tobacco by ${ }^{13} \mathrm{C}$ NMR spectroscopy. Cellulose, 22(4): 2693-2702. 